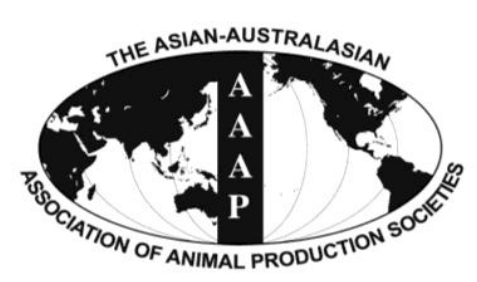

Open Access

Asian Australas. J. Anim. Sci.

Vol. 28, No. 6 : 862-869 June 2015

http://dx.doi.org/10.5713/ajas.14.0768

www.ajas.info

pISSN 1011-2367 elSSN 1976-5517

\title{
Estimation of Pork Quality Traits Using Exsanguination Blood and Postmortem Muscle Metabolites
}

\author{
J. H. Choe, M. H. Choi, Y. C. Ryu ${ }^{1}$, G. W. Go ${ }^{2}$, Y. M. Choi ${ }^{3}$, S. H. Lee', K. S. Lim ${ }^{5}$, E. A. Lee, \\ J. H. Kang ${ }^{5}$, K. C. Hong ${ }^{5}$, and B. C. Kim* \\ Department of Food Bioscience and Technology, Korea University, Seoul 136-701, Korea
}

\begin{abstract}
The current study was designed to estimate the pork quality traits using metabolites from exsanguination blood and postmortem muscle simultaneously under the Korean standard pre- and post-slaughter conditions. A total of 111 Yorkshire (pure breed and castrated male) pigs were evaluated under the Korean standard conditions. Measurements were taken of the levels of blood glucose and lactate at exsanguination, and muscle glycogen and lactate content at $45 \mathrm{~min}$ and $24 \mathrm{~h}$ postmortem. Certain pork quality traits were also evaluated. Correlation analysis and multiple regression analysis including stepwise regression were performed. Exsanguination blood glucose and lactate levels were positively correlated with each other, negatively related to postmortem muscle glycogen content and positively associated with postmortem muscle lactate content. A rapid and extended postmortem glycolysis was associated with high levels of blood glucose and lactate, with high muscle lactate content, and with low muscle glycogen content during postmortem. In addition, these were also correlated with paler meat color and reduced water holding capacity. The results of multiple regression analyses also showed that metabolites in exsanguination blood and postmortem muscle explained variations in pork quality traits. Especially, levels of blood glucose and lactate and content of muscle glycogen at early postmortem were significantly associated with an elevated early glycolytic rate. Furthermore, muscle lactate content at $24 \mathrm{~h}$ postmortem alone accounted for a considerable portion of the variation in pork quality traits. Based on these results, the current study confirmed that the main factor influencing pork quality traits is the ultimate lactate content in muscle via postmortem glycolysis, and that levels of blood glucose and lactate at exsanguination and contents of muscle glycogen and lactate at postmortem can explain a large portion of the variation in pork quality even under the standard slaughter conditions. (Key Words: Exsanguination, Glucose, Glycogen, Lactate, Postmortem Glycolysis, Pork Quality)
\end{abstract}

\section{INTRODUCTION}

Technological meat quality includes meat color, water

\footnotetext{
* Corresponding Author: B. C. Kim. Tel: +82-2-3290-3052, Fax: +82-2-3290-4984, E-mail: bckim@korea.ac.kr

1 College of Applied Life Sciences, Sustainable Agriculture Research Institute, Jeju National University, Jeju 690-756, Korea.

${ }^{2}$ Department of Food and Nutrition, Kookmin University, Seoul 136-702, Korea.

${ }^{3}$ Department of Animal Sciences and Biotechnology, KyungPook National University, Sangju 742-711, Korea.

4 Department of Nutritional Science and Food Management, Ewha University, Seoul 120-750, Korea.

${ }^{5}$ Division of Biotechnology, Korea University, Seoul 136-701, Korea.
}

Submitted Oct. 1, 2014; Revised Nov. 17, 2014; Accepted Dec. 9, 2014 holding capacity (WHC), and texture properties (Warner et al., 2010; Lee et al., 2012). These properties are developed by the rate and extent of postmortem anaerobic glycolysis. A paler lean meat color, decreased WHC, and soft texture, such as found in pale, soft, and exudative (PSE) meat, is the deteriorative condition of pork. An accelerated rate of postmortem glycolysis is considered to be a primary cause of PSE meat (Bowker et al., 2000; Scheffler and Gerrard, 2007). During postmortem, muscles produce adenosine triphosphate via anaerobic glycolysis (i.e. catabolize muscle glycogen into lactate). This lactate accumulates in the muscle, resulting in a muscle $\mathrm{pH}$ decline which causes the denaturation of muscle proteins. A rapid decline in muscle $\mathrm{pH}$ at early postmortem while muscle temperature is still high causes severe denaturation of the myofibrillar and sarcoplasmic proteins (Ryu and Kim, 2006; Scheffler and

Copyright @ 2015 by Asian-Australasian Journal of Animal Sciences This is an open-access article distributed under the terms of the Creative Commons Attribution Non-Commercial License (http://creativecommons.org/licenses/by-nc/3.0/), which permits unrestricted non-commercial use, distribution, and reproduction in any medium, provided the original work is properly cited. 
Gerrard, 2007). So, measurement of postmortem muscle glycogen and lactate content could help to explain variations in postmortem glycolysis and subsequently pork quality (Kocwin-Podsiadla et al., 2006). Ryu et al. (2005) and Choe et al. (2008) also showed that higher contents of muscle glycogen and lactate at early postmortem was related to paler color and higher drip loss of pork.

There are numerous factors influencing postmortem metabolism, one of which is pre-slaughter stress. In general, stress immediately before slaughter accelerates postmortem glycolysis, resulting in PSE meat in pigs. Hormones and metabolite levels in blood are frequently used to measure livestock stress level. Blood cortisol and lactate levels, particularly, have been used as reliable indicators in many studies (Warriss, 1990; Hambrecht et al., 2004; 2005a, b; Edwards et al., 2010a, b; Choe and Kim, 2014). In addition, Choe and Kim (2014) and Choe et al. (2009) showed that the blood glucose level at exsanguination could be an indicator of stress and that it is strongly associated with pork quality traits. Furthermore, previous studies (Edwards et al., 2010a, b; Choe and Kim, 2014) showed that there are considerable variation in blood glucose and lactate levels although the experimental pigs were under the same standard slaughter conditions. However, most studies about pre-slaughter stress and metabolism imposed artificial stress on livestock. Moreover, there is limited research about the relationship between metabolites from blood and muscle and meat quality simultaneously. There are also few reports investigating how metabolites influence ultimate pork quality traits. Therefore, the objective was to estimate the pork quality traits using metabolites from exsanguination blood and postmortem muscle simultaneously under the Korean standard pre- and post-slaughter conditions.

\section{MATERIALS AND METHODS}

\section{Animals, pre-slaughter handling, and slaughter procedure}

All experimental conditions were in accordance with the Korean Animal Protection Act, including detailed provision for transport and slaughter. Treatments, handling conditions, and experimental procedures were controlled and/or approved by the Ministry of Agriculture, Food, and Rural Affairs of South Korea. Slaughter procedure was under the supervision of the Korea Institute for Animal Products Quality Evaluation.

A total of 111 Yorkshire (pure breed castrated male) pigs were evaluated. All pigs were non-carriers of the halothane gene and clinically healthy. The treatment conditions, both before and after slaughter, were same for all pigs. The pigs were divided randomly into different pens in a commercial farm, with a stocking density of $1.0 \mathrm{~m}^{2}$ per pig. The temperature was maintained at $20 \pm 2^{\circ} \mathrm{C}$, and artificial light was provided from 0900 to 2100 . Water and food were available ad libitum at nipple drinkers and food dispensers. In addition, all pigs were fed the same commercial diet in accordance with the National Research Council (1998). When the pigs reached a live weight of $115 \pm 5 \mathrm{~kg}$, they were transported to a commercial slaughter facility. Approximately $4 \mathrm{~h}$ before transport, feed was withdrawn. The loading and unloading took place as parallel to the ground as possible. Electric prods were not used during loading or unloading. The truck had two straight decks, and a hydraulic lift raised the floor of the deck to create the second deck. The truck was equipped with natural ventilation, and the stocking density was approximately $0.47 \mathrm{~m}^{2}$ per pig. The pigs were transported for $1 \mathrm{~h}$ to the slaughter facility. The pigs were not mixed with unfamiliar pigs during transport or lairage. To reduce stress during lairage, the pigs were showered with water and provided with drinking water ad libitum. After being rested for approximately $12 \mathrm{~h}$ at the slaughter facility, the pigs were slaughtered. All the pigs were slaughtered during the winter period in one of 4 batches $(30,30,30$, and 21 pigs per batch). The pigs were immobilized through electrical stunning ( 2 to $4 \mathrm{~s}$ with over $1.25 \mathrm{~A}$ ), shackled by the right leg, and exsanguinated while hanging. At exsanguination, blood samples were collected from each pig. A dehairing process was performed in a scalding-singeing combination by scalding for $3 \mathrm{~min}$ at $60^{\circ} \mathrm{C}$, and then singeing via passing through gas burner for $10 \mathrm{~s}$ at $1,200^{\circ} \mathrm{C}$, and any remaining hair was removed using a knife and flame. The carcasses were eviscerated, split into the left and right sides, and then cooled in the chilling room $\left(4^{\circ} \mathrm{C}\right)$.

At 45 min postmortem, muscle samples for the analysis of glycogen and lactate contents were taken from the longissimus lumborum muscle at the 9th and 10th thoracic vertebrae. After $24 \mathrm{~h}$ of chilling, muscle samples for the measurement of muscle glycogen and lactate contents and pork quality traits were taken from the longissimus lumborum muscle at the 10th and 15th thoracic vertebrae. The collection of all muscle samples and $\mathrm{pH}$ measurements was made on the right side of each carcass.

\section{Blood samples and blood metabolites measurements}

Blood samples were collected from each pig at exsanguination after electrical stunning. The blood samples were collected using tubes treated with potassium oxalate/sodium fluoride (BD Vacutainer fluoride tube; Becton Dickinson, Franklin Lakes, New Jersey, USA) to inhibit further glycolysis. Blood glucose and lactate levels were then measured using hand-held devices (blood glucose: OneTouch Ultra, LifeScan, Inc., Milpitas, California, USA; blood lactate: Lactate Scout, EKF Diagnostics, Barleben, Magdeburg, Germany). All measurements were completed within $10 \mathrm{~min}$ of exsanguination at the slaughter facility. Blood glucose level 
was expressed in milligrams per deciliter $(\mathrm{mg} / \mathrm{dL})$, and blood lactate level was expressed in millimoles per liter $(\mathrm{mmol} / \mathrm{L})$.

\section{Measurement of muscle glycogen and lactate contents}

Glycogen content of muscle was measured via the method described by Dreiling et al. (1987). Approximately $1.5 \mathrm{~g}$ of tissue was minced, suspended in $10 \mathrm{~mL}$ of $9 \%$ cold perchloric acid (PCA), and thoroughly homogenized for 30 to $45 \mathrm{~s}$ with a mechanical tissue disrupter. After centrifugation $\left(15,000 \times g\right.$ at $\left.4^{\circ} \mathrm{C}\right)$, the supernatant was decanted and saved for glycogen determination. An iodine color reagent was prepared by combining $100 \mathrm{~mL}$ of saturated $\mathrm{CaCl}_{2}$ with $1.3 \mathrm{~mL}$ of the solution $(0.26 \mathrm{~g}$ of iodine, $2.6 \mathrm{~g}$ of potassium iodide in $10 \mathrm{~mL}$ of distilled water) (prepared freshly every day). The $2.6 \mathrm{~mL}$ of the iodine color reagent was added to $0.4 \mathrm{~mL}$ of the glycogen standards or tissue extracts. In this way, glycogen standard curves were developed for each set of samples so that linear regression equations could be used to determine the glycogen concentrations of the test samples.

Lactate content was determined spectrophotometrically at $340 \mathrm{~nm}$ using a commercial kit (Boehringer-Mannheim, Darmstadt, Germany). Approximately $500 \mathrm{mg}$ of muscle was homogenized for $30 \mathrm{~s}$ in $2 \mathrm{~mL}$ of $1 \mathrm{M}$ PCA. Potassium hydroxide ( $2 \mathrm{M})$ was added to neutralize the solution, and distilled water was added to make a final volume of $10 \mathrm{~mL}$. After 20 min of refrigeration and centrifugation, lactic acid concentration was measured.

\section{Pork quality evaluation}

Muscle $\mathrm{pH}$ at 45 min postmortem $\left(\mathrm{pH}_{45 \min }\right)$ and $24 \mathrm{~h}$ postmortem $\left(\mathrm{pH}_{24} \mathrm{~h}\right)$ was measured in the chilling room directly at the 7th and 8th thoracic vertebrae of each carcass (right side) using a portable pH meter for meat (HI 99163, Hanna instruments, Woonsocket, Rhode Island, USA).

For analysis of meat color, WHC, and Warner-Bratzler shear force (WBS), samples were obtained from the pork loin at the 10th to 15th thoracic vertebrae from the right side of each cold carcass. Meat color was measured with a Minolta Chroma Meter (CR-400, Minolta Camera Co., Tokyo, Japan), following a slightly modified version of the method of Honikel (1998). Samples were cut from the pork loin at $24 \mathrm{~h}$ postmortem and placed on a table for $30 \mathrm{~min}$, exposing their surfaces to air without any packaging (for bloom) before color measurement. Triplicate measurements were averaged, and the results were expressed as Commission Internationale de l'Eclairage lightness $\left(L^{*}\right)$, redness $\left(a^{*}\right)$, and yellowness $\left(b^{*}\right)$.

To evaluate the WHC, drip loss, cooking loss (Honikel, 1998), and filter-paper fluid uptake (FFU) (Kauffman et al., 1986) were measured. To determine drip loss, meat samples were cut from the pork loin at $24 \mathrm{~h}$ postmortem and weighed immediately to obtain their initial weight of drip loss. The samples were then placed in netting and suspended in an inflated bag, ensuring that the sample was not in contact with the bag. After a $48 \mathrm{~h}$ storage period at $4^{\circ} \mathrm{C}$, the samples were taken from the bag, gently blotted dry, and reweighed. Drip loss was expressed as a percentage of the sample's initial weight. To measure cooking loss of water, different samples were freshly cut from the pork loin at $24 \mathrm{~h}$ postmortem and weighed to obtain their initial weight. The samples were then put in thin-walled polyethylene bags and placed in a continuously boiling water bath. The samples were cooked to $75^{\circ} \mathrm{C}$ internal temperature and, once this end-point temperature had been reached, the bags were removed from the water bath. Thereafter, the samples were cooled in an ice slurry and kept under chilled conditions $\left(1^{\circ} \mathrm{C}\right.$ to $\left.5^{\circ} \mathrm{C}\right)$ until equilibration. Then, the samples were taken from the bag, blotted dry, and reweighed. Cooking loss was expressed as a percentage of the sample's initial weight. For FFU, further samples were cut from the pork loin at $24 \mathrm{~h}$ postmortem. Filter paper (Whatman \#2, $42.5 \mathrm{~mm}$ in diameter, GE Healthcare, Little Chalfont, Buckinghamshire, UK) was pre-weighed, placed on the surface of the sample for just under $2 \mathrm{~s}$ to absorb fluids, and weighed. The FFU was expressed as milligrams of exudate absorbed into the filter paper.

To measure WBS, the pork loin was cut into $20-\mathrm{mm}$ thick chops. Pork chops from each sample were cooked to a final core temperature of $75^{\circ} \mathrm{C}$ in a continuously boiling water bath. After cooking, six cores (1.27 cm in diameter), parallel to the longitudinal orientation of the muscle fibers, were taken from each pork chop for WBS measurement. WBS was determined using an Instron Universal Testing Machine (Model Series IX, Instron Co., Norwood, MA, USA) with a Warner-Bratzler shearing device. The samples were sheared perpendicular to the long axis of the core, and the WBS value was calculated taken from the peak of the force curve (Honikel, 1998).

\section{Statistical analysis}

All statistical analysis was performed using the Statistical Analysis System (2009). Pearson correlation coefficients between blood and muscle metabolites or between blood and muscle metabolites and pork quality traits were determined using the CORR procedure. To establish multiple regression models for pork quality traits, blood or muscle metabolites were used as independent variables in the REG procedure. Furthermore, the stepwise procedure was used to examine the percentage of variation in certain pork quality traits explained by blood and muscle metabolites. The qualitative variable (batch) was coded as 
Table 1. Correlation coefficients between blood glucose and lactate levels and muscle glycogen and lactate contents

\begin{tabular}{|c|c|c|c|c|c|}
\hline & Blood lactate & Muscle glycogen ${ }_{45 \mathrm{~min}}$ & Muscle lactate $_{45 \text { min }}$ & Muscle glycogen $_{24 \mathrm{~h}}$ & Muscle lactate $_{24 \mathrm{~h}^{3}}$ \\
\hline Blood glucose $^{1}$ & $0.46^{* * *}$ & $-0.25 * *$ & $0.51 * * *$ & $-0.35 * * *$ & $0.47 * * *$ \\
\hline Blood lactate $^{1}$ & & $-0.28 * *$ & $0.39 * * *$ & -0.10 & $0.24 *$ \\
\hline Muscle glycogen ${ }_{45 \min }^{2}$ & & & $-0.47 * * *$ & 0.05 & $-0.28 * *$ \\
\hline Muscle lactate $_{45 \min }{ }^{2}$ & & & & $-0.27 * *$ & $0.44 * * *$ \\
\hline Muscle glycogen $24 \mathrm{~h}^{3}$ & & & & & $-0.25 * *$ \\
\hline
\end{tabular}

${ }^{1}$ Blood glucose $(\mathrm{mg} / \mathrm{dL})$ and lactate $(\mathrm{mmol} / \mathrm{L})$ level measured at exsanguination.

${ }^{2}$ Muscle glycogen and lactate content $(\mathrm{mg} / \mathrm{g})$ measured at $45 \mathrm{~min}$ postmortem.

${ }^{3}$ Muscle glycogen and lactate content $(\mathrm{mg} / \mathrm{g})$ measured at $24 \mathrm{~h}$ postmortem.

$* \mathrm{p}<0.05 ; * * \mathrm{p}<0.01 ; * * * \mathrm{p}<0.001$.

dummy variables to eliminate their effect on the regression model.

\section{RESULTS}

Correlation between levels of blood glucose and lactate and contents of muscle glycogen and lactate

Table 1 shows the correlation coefficients between the following variables: exsanguination blood glucose and lactate levels and postmortem muscle glycogen and lactate contents. Levels of blood glucose and lactate showed a positive relationship. Blood glucose level was negatively related to muscle glycogen content at postmortem (i.e. 45 min and $24 \mathrm{~h}$ postmortem) but positively correlated with muscle lactate content at postmortem. Blood lactate level was also negatively related to muscle glycogen content at $45 \mathrm{~min}$ postmortem and positively correlated with muscle lactate content at postmortem. These relationships mean that high levels of blood glucose and lactate are associated with not only rapid glycolytic rate at early postmortem (glycogen and lactate contents measured at $45 \mathrm{~min}$ postmortem) but also extended postmortem glycolysis (glycogen and lactate contents measured at $24 \mathrm{~h}$ postmortem). There are negative correlations between postmortem muscle glycogen and lactate contents.

Correlation between blood and muscle metabolites and pork quality traits

There are significant relationships between metabolites in exsanguination blood and postmortem muscle and $\mathrm{pH}$, lightness, and WHC (Table 2). Blood glucose level is negatively related to muscle $\mathrm{pH}_{45}$ min and $\mathrm{pH}_{24} \mathrm{~h}$ and positively correlated to lightness, FFU, and drip loss. Blood lactate level is also negatively related to postmortem muscle $\mathrm{pH}$ and positively correlated with FFU and drip loss. Higher levels of exsanguination blood metabolites were associated with paler color and decreased WHC.

Muscle glycogen content at $45 \mathrm{~min}$ postmortem had a positive relationship with muscle $\mathrm{pH}_{45}$ min and negative relationship with lightness, FFU, and drip loss. Muscle glycogen content at $24 \mathrm{~h}$ postmortem exhibited similar relationships, except that it was significantly correlated with muscle $\mathrm{pH}_{24} \mathrm{~h}$, rather than muscle $\mathrm{pH}_{45}$ min. On the other hand, muscle lactate content at both $45 \mathrm{~min}$ and $24 \mathrm{~h}$ postmortem were negatively related to postmortem muscle $\mathrm{pH}$ and positively correlated with lightness, FFU, and drip loss. Lower glycogen content and higher lactate content in postmortem muscle were correlated with deteriorative pork quality.

\section{Influence of blood and muscle metabolites with pork quality traits}

Multiple regression analysis including stepwise regression was performed to investigate the influence of exsanguination blood metabolites (Table 3), postmortem muscle metabolites (Table 4), or both the blood and muscle metabolites together (Table 5) on pork quality traits. Levels of blood glucose and lactate at exsanguination explained

Table 2. Correlation coefficients between blood and muscle metabolites and certain pork quality traits

\begin{tabular}{|c|c|c|c|c|c|c|c|}
\hline & $\mathrm{pH}_{45 \min }$ & $\mathrm{pH}_{24 \mathrm{~h}}$ & Lightness & FFU & Drip loss & Cooking loss & WBS \\
\hline Blood glucose $^{1}$ & $-0.41 * * *$ & $-0.51 * * *$ & $0.25 * *$ & $0.35 * * *$ & $0.32 * * *$ & 0.01 & -0.16 \\
\hline Blood lactate $^{1}$ & $-0.40 * * *$ & $-0.20 *$ & 0.15 & $0.41 * * *$ & $0.35^{* * *}$ & 0.10 & $-0.26 * *$ \\
\hline Muscle glycogen $45 \min ^{2}$ & $0.67 * * *$ & -0.01 & $-0.23^{*}$ & $-0.20 *$ & $-0.34 * * *$ & $-0.20^{*}$ & 0.14 \\
\hline Muscle lactate $_{45 \min ^{2}}$ & $-0.53 * * *$ & $-0.30 * *$ & $0.20 *$ & $0.33 * * *$ & $0.32 * * *$ & 0.02 & -0.18 \\
\hline Muscle glycogen $24 \mathrm{~h}^{3}$ & 0.16 & $0.40 * * *$ & $-0.28 * *$ & $-0.25 * *$ & $-0.22 *$ & -0.04 & 0.04 \\
\hline Muscle lactate $_{24 \mathrm{~h}^{3}}$ & $-0.30^{* *}$ & $-0.55 * * *$ & $0.53 * * *$ & $0.51 * * *$ & $0.61 * * *$ & 0.14 & -0.09 \\
\hline
\end{tabular}

FFU, filter-paper fluid uptake; WBS, Warner-Bratzler shear force.

${ }^{1}$ Blood glucose $(\mathrm{mg} / \mathrm{dL})$ and lactate $(\mathrm{mmol} / \mathrm{L})$ level measured at exsanguination.

${ }^{2}$ Muscle glycogen and lactate content $(\mathrm{mg} / \mathrm{g}$ ) measured at $45 \mathrm{~min}$ postmortem.

${ }^{3}$ Muscle glycogen and lactate content $(\mathrm{mg} / \mathrm{g})$ measured at $24 \mathrm{~h}$ postmortem.

$* \mathrm{p}<0.05 ; * * \mathrm{p}<0.01$; *** $\mathrm{p}<0.001$. 
Table 3. Multiple regression models for certain pork quality traits using blood glucose and lactate levels measured at exsanguination

\begin{tabular}{|c|c|c|c|c|c|}
\hline \multirow{2}{*}{ Pork quality traits } & \multirow{2}{*}{ Intercept } & \multicolumn{2}{|c|}{ Blood metabolites level } & \multirow{2}{*}{$R^{2}$} & \multirow{2}{*}{ Significance } \\
\hline & & Glucose $^{1}$ & Lactate $^{1}$ & & \\
\hline $\mathrm{pH}_{45 \text { min }}$ & 6.534 & -0.001 & -0.014 & 0.218 & $* * *$ \\
\hline $\mathrm{pH}_{24 \mathrm{~h}}$ & 5.794 & -0.001 & -0.001 & 0.240 & $* * *$ \\
\hline Lightness & 43.607 & 0.015 & 0.022 & 0.086 & $*$ \\
\hline FFU & 4.062 & 0.061 & 1.086 & 0.210 & $* * *$ \\
\hline Drip loss & 1.196 & 0.007 & 0.105 & 0.162 & $* * *$ \\
\hline WBS & 64.089 & -0.002 & -0.680 & 0.074 & $*$ \\
\hline
\end{tabular}

FFU, filter-paper fluid uptake; WBS, Warner-Bratzler shear force.

${ }^{1}$ Blood glucose $(\mathrm{mg} / \mathrm{dL})$ and lactate $(\mathrm{mmol} / \mathrm{L})$ level measured at exsanguination.

$* \mathrm{p}<0.05 ; * * * \mathrm{p}<0.001$

$21.8 \%$ and $24 \%$ of the variation in muscle $\mathrm{pH}_{45}$ min and $\mathrm{pH}_{24 \mathrm{~h}}$, respectively. They also accounted for $21 \%$ and $16.2 \%$ of the variation in FFU and drip loss, respectively. On the other hand, compared to blood metabolite levels, contents of muscle glycogen and lactate at postmortem explained a higher proportion of the variation in pork quality traits. Over $40 \%$ of the variability in postmortem muscle $\mathrm{pH}$ was explained by muscle metabolite content. Metabolites contents in postmortem muscle accounted for over $40 \%$ of the variation in lightness and drip loss. The variability of FFU was also explained up to $31.2 \%$ by muscle metabolite content.

When a stepwise regression analysis using metabolites from both exsanguination blood and postmortem muscle was carried out, the variability of pork quality traits was explained slightly further. Blood metabolites and muscle metabolites at 45 min postmortem accounted for $54.4 \%$ of variation in muscle $\mathrm{pH}_{45}$ min. In the case of muscle $\mathrm{pH}_{24} \mathrm{~h}$, $46.2 \%$ of the variation was explained by blood and muscle metabolites. In fact, muscle lactate content at $24 \mathrm{~h}$ postmortem alone accounted for $30.1 \%$ of the variation. Variability of lightness, FFU, and drip loss showed similar

Table 4. Multiple regression models for certain pork quality traits using muscle glycogen and lactate contents measured at 45 min and 24 h postmortem

\begin{tabular}{lccccccc}
\hline \multirow{2}{*}{ Pork quality traits } & \multirow{2}{*}{ Intercept } & \multicolumn{4}{c}{ Muscle metabolites content } & \multirow{2}{*}{$R^{2}$} & \multirow{2}{*}{ Significance } \\
\cline { 3 - 6 } & & Glycogen $_{45 \text { min }}{ }^{1}$ & Lactate $_{45 \text { min }}{ }^{2}$ & Glycogen $_{24 \mathrm{~h}}{ }^{2}$ & Lactate $_{24 \mathrm{~h}}{ }^{2}$ & & \\
$\mathrm{pH}_{45 \text { min }}$ & 6.030 & 0.557 & 0.261 & -0.048 & -0.026 & 0.522 & $* * *$ \\
$\mathrm{pH}_{24 \mathrm{~h}}$ & 6.503 & -0.130 & 0.627 & -0.018 & -0.106 & 0.414 & $* * *$ \\
Lightness & 32.495 & -1.936 & -9.814 & -0.247 & 2.244 & 0.406 & $* * *$ \\
FFU & -47.565 & -4.315 & -35.495 & 1.063 & 10.267 & 0.312 & $* * *$ \\
Drip loss & -6.489 & -1.348 & -3.011 & 0.012 & 1.455 & 0.435 & $* * *$ \\
Cooking loss & 25.764 & -2.818 & 0.161 & -0.025 & 0.800 & 0.101 & $*$ \\
\hline
\end{tabular}

FFU, filter-paper fluid uptake.

${ }^{1}$ Muscle glycogen and lactate content $(\mathrm{mg} / \mathrm{g})$ measured at $45 \mathrm{~min}$ postmortem.

${ }^{2}$ Muscle glycogen and lactate content $(\mathrm{mg} / \mathrm{g})$ measured at $24 \mathrm{~h}$ postmortem.

$* \mathrm{p}<0.05 ; * * * \mathrm{p}<0.001$

Table 5. Proportion of variability in certain pork quality traits explained by blood and muscle metabolites using stepwise regression

\begin{tabular}{|c|c|c|c|c|c|c|c|}
\hline & $\mathrm{pH}_{45 \min }$ & $\mathrm{pH}_{24 \mathrm{~h}}$ & Lightness & FFU & Drip loss & Cooking loss & WBS \\
\hline \multicolumn{8}{|c|}{ Blood metabolites measured at exsanguination } \\
\hline Glucose & $7.9^{1, * * *}$ & $9.0 * * *$ & & & & & \\
\hline Lactate & $1.7 * *$ & & & $9.2 * * *$ & $4.8^{* *}$ & & $7.3^{* *}$ \\
\hline \multicolumn{8}{|c|}{ Muscle metabolites measured at $45 \mathrm{~min}$ postmortem } \\
\hline Glycogen & $44.8 * * *$ & $3.9^{*}$ & 1.7 & & $2.2 *$ & $7.3^{* *}$ & \\
\hline Lactate & & & & & & & \\
\hline \multicolumn{8}{|c|}{ Muscle metabolites measured at $24 \mathrm{~h}$ postmortem } \\
\hline Glycogen & & $3.2 *$ & $2.5 *$ & 1.6 & & & \\
\hline Lactate & & $30.1 * * *$ & $35.5 * * *$ & $27.7 * * *$ & $39.1 * * *$ & 2.8 & \\
\hline Cumulative contribution & 54.4 & 46.2 & 39.7 & 38.5 & 46.2 & 10.1 & 7.3 \\
\hline
\end{tabular}

FFU, filter-paper fluid uptake; WBS, Warner-Bratzler shear force.

${ }^{1}$ Percentage of partial $R^{2}$

$* \mathrm{p}<0.05 ; * * \mathrm{p}<0.01 ; * * * \mathrm{p}<0.001$ 
tendencies, with muscle lactate content at $24 \mathrm{~h}$ postmortem alone explaining a considerable portion of the variation once again.

\section{DISCUSSION}

One of the interesting subjects in meat science is preslaughter stress because pre-slaughter stress causes variations in postmortem muscle metabolism and subsequently influences meat quality (Warriss, 1990; D’Souza et al., 1998a, b; Faucitano, 1998; Hambrecht et al., 2004; 2005a, b; Edwards et al., 2010a, b; Koknaroglu and Akunal, 2013; Choe and Kim, 2014). Specifically, stress just before slaughter accelerates the glycolytic rate, resulting in rapid decline in muscle $\mathrm{pH}$ and consequently deteriorative meat quality (D'Souza et al., 1998a, b; van der Wal et al., 1999; Hambrecht et al., 2004; 2005a; Edwards et al., 2010a). Blood glucose and lactate levels at exsanguination are usually used to measure livestock stress levels. Blood lactate level is one of the most reliable indicators of stress level and is partially associated with meat quality (Warriss et al., 1994; Hambrecht et al., 2004; 2005a, b; Edwards et al., 2010a, b; Warriss, 2010; Choe and Kim, 2014). On the other hand, blood glucose level is an indirect indicator of stress because there are numerous factors which influence blood glucose level (Shaw and Tume, 1992; Mota-Rojas et al., 2012; Choe and Kim, 2014). Nevertheless, Choe and Kim (2014) and Choe et al. (2009) showed that blood glucose and lactate levels at exsanguination were significantly related to pork quality traits.

In the current study, exsanguination blood glucose and lactate levels were positively related with each other. Similarly, Choe and Kim (2014) showed that blood glucose levels are positively correlated with blood lactate and cortisol levels. A physiological response to stress is the activation of two main neuroendocrine systems, the hypothalamic-pituitary-adrenocortical (HPA) axis and the sympathetic nervous system. Stimulating the HPA axis releases cortisol, which elevates blood glucose level via gluconeogenesis (Warriss, 2010). Stimulating the sympathoadrenal system leads to an increase in blood glucose level due to a rapid breakdown of liver glycogen. In addition, livestock consume energy via anaerobic glycolysis under stressful conditions, resulting in increased blood lactate level (Warriss, 2010; Foury et al., 2011; Choe and Kim, 2014).

Kocwin-Podsiadla et al. (2006) have reported that the change of metabolite levels in postmortem muscle indicates normal and deteriorative quality meat, such as PSE and acid meat. Especially, glycogen and lactate contents in the muscle were the significant indicator of muscle $\mathrm{pH}$ change and ultimate quality conditions. Choe et al. (2008) also showed that different levels of glycogen and lactate content in postmortem muscle can explain the rate and extent of postmortem glycolysis. In that study, muscle lactate content at early postmortem was associated with the early postmortem glycolytic rate, while muscle glycogen content at early postmortem was related to ultimate muscle $\mathrm{pH}$. Similarly, the current study showed that blood glucose and lactate levels were negatively related to postmortem muscle glycogen content and positively correlated with muscle lactate content. Exsanguination blood metabolite levels were also associated with a rapid and extended postmortem glycolysis. Furthermore, muscle lactate content at early postmortem was negatively correlated with muscle $\mathrm{pH}_{45}$ min . However, there was no significant relationship between the muscle glycogen content measured at 45 min postmortem and muscle $\mathrm{pH}_{45}$ min. Similar results were observed in the study of Edwards et al. (2010a), showing that exsanguination blood lactate level was negatively related to muscle $\mathrm{pH}$ measured at $60 \mathrm{~min}$ postmortem. D'Souza et al. (1998a) reported that muscles with lower glycogen and higher lactate content caused by handling stress showed lower muscle pH postmortem. Hambrecht et al. (2004; 2005a) also observed similar results.

The rate and extent of postmortem $\mathrm{pH}$ decline have a strong impact on the development of pork quality (D'Souza et al., 1998a, b; Kocwin-Podsiadla et al., 2006; Ryu and Kim, 2006; Scheffler and Gerrard, 2007). A rapid and extended postmortem glycolysis causes severe denaturation of myofibrillar and sarcoplasmic proteins (Joo et al., 1999). It is obvious that severely denatured muscle proteins have a negative effect on pork quality, resulting in both a lighter color and reduced WHC. D'Souza et al. (1998a) showed that low glycogen and high lactate content during postmortem due to poor handling just prior to slaughter caused a rapid glycolytic rate, high amounts of exudate, and a high incidence of PSE meat. Hambrecht et al. (2005a, b) similarly reported that low glycogen and high lactate at postmortem decrease WHC. Ryu et al. (2005) showed that high muscle lactate content at $24 \mathrm{~h}$ postmortem was closely correlated with decreased muscle $\mathrm{pH}$, reduced protein solubility, paler color, and high fluid loss. KocwinPodsiadla et al. (2006) have reported that the change in postmortem muscle $\mathrm{pH}$ can be used to diagnose normal and deteriorative meat. In addition, Choe et al. (2009) and Choe and Kim (2014) showed that high levels of blood glucose and lactate levels were also significantly correlated with deteriorative pork quality. As expected, the results of the current study were consistent with those of previous ones. Paler colors and high amounts of fluid loss were significantly associated with high levels of blood glucose and lactate at exsanguination and low contents of glycogen and high lactate in postmortem muscle. Particularly, correlation coefficients between muscle lactate content at $24 \mathrm{~h}$ postmortem and muscle $\mathrm{pH}_{24} \mathrm{~h}$, lightness, FFU, and drip loss, respectively, had higher values than others. This 
confirmed again that pork quality traits are significantly affected by the accumulation of lactate from postmortem glycolysis.

Hambrecht et al. (2004) reported that blood lactate level and glycolytic potential explained a considerable portion of the variation in lightness and drip loss. Blood lactate level alone explained about $30 \%$ of the variation in lightness and drip loss but blood lactate level and glycolytic potential together could explain about 50\% (Hambrecht et al., 2004). In the current study, exsanguination blood glucose and lactate levels explained approximately $20 \%$ of the variation in muscle $\mathrm{pH}$ and FFU, and about $15 \%$ of the variation in drip loss. On the other hand, muscle glycogen and lactate content measured at $45 \mathrm{~min}$ and $24 \mathrm{~h}$ postmortem accounted for $31 \%$ to $52 \%$ of variation in muscle $\mathrm{pH}$, lightness, FFU, and drip loss. The study of Hambrecht et al. (2004) imposed pre-slaughter stress on experimental pigs, but in the current study, all experimental pigs were under the Korean standard pre-slaughter condition. This difference may explain the lower $R^{2}$ values of the result of multiple regression analysis in the present study compared to those of Hambrecht et al. (2004).

Stepwise regression analysis is a type of multiple regression analysis for selecting independent variables that have an impact on the dependent ones or can explain a higher proportion of their variation (Lee et al., 2012). The current study showed that levels of blood glucose and lactate at exsanguination and muscle glycogen content at 45 min postmortem explained $54.4 \%$ of the variation in muscle $\mathrm{pH}_{45 \text { min. }}$ On the other hand, muscle lactate content at $24 \mathrm{~h}$ postmortem accounted for a considerable portion of the variability of muscle $\mathrm{pH}_{24}$, lightness, FFU, and drip loss. Other metabolite concentrations in blood and muscle accounted for a small portion of variation in pork quality traits.

\section{CONCLUSION}

The current study showed that high levels of exsanguination blood glucose and lactate were associated low content of glycogen and high content of lactate in postmortem muscle. In addition, these metabolite levels were associated with accelerated and extended postmortem anaerobic glycolysis, resulting in paler color and reduced WHC. Stepwise regression also showed metabolite levels from exsanguination blood and postmortem muscle accounted for up to $54.5 \%$ of variation in pork quality. Especially, ultimate lactate content in postmortem muscle explained a considerable variation $(27.7 \%$ to $39.1 \%)$ in pork quality traits. These results indicated that a major factor which effects pork quality is the ultimate lactate content in muscle through postmortem glycolysis and that exsanguination blood glucose and lactate levels and postmortem muscle glycogen and lactate contents can explain a large portion of the variation in pork quality even under the standard slaughter conditions.

\section{ACKNOWLEDGMENTS}

This research was supported by a Korea University Grant. The authors thank the Institute of Biomedical Science and Food Safety, Korea University Food Safety Hall, for providing the equipment and facilities.

\section{REFERENCES}

Bowker, B. C., A. L. Grant, J. C. Forrest, and D. E. Gerrard. 2000. Muscle metabolism and PSE pork. J. Anim. Sci. 79(e-suppl):18.

Choe, J. H. and B. C. Kim. 2014. Association of blood glucose, blood lactate, serum cortisol levels, muscle metabolites, muscle fiber type composition, and pork quality traits. Meat Sci. 97:137-142.

Choe, J. H., Y. M. Choi, S. H. Lee, Y. J. Nam, Y. C. Jung, H. C. Park, Y. Y. Kim, and B. C. Kim. 2009. The relation of blood glucose level to muscle fiber characteristics and pork quality traits. Meat Sci. 83: 62-67.

Choe, J. H., Y. M. Choi, S. H. Lee, H. G. Shin, Y. C. Ryu, K. C. Hong, and B. C. Kim. 2008. The relation between glycogen, lactate content and muscle fiber type composition, and their influence on postmortem glycolytic rate and pork quality. Meat Sci. 80:355-362.

D’Souza, D. N., F. R. Dunshea, R. D. Warner, and B. J. Leury. 1998a. The effect of handling pre-slaughter and carcass processing rate post-slaughter on pork quality. Meat Sci. 50: 429-437.

D'Souza, D. N., B. J. Leury, F. R. Dunshea, and R. D. Warner. 1998b. Effect of on-farm and pre-slaughter handling of pigs on meat quality. Aust. J. Agric. Res. 49:1021-1025.

Dreiling, C. E., D. E. Brown, L. Casale, and L. Kelly. 1987. Muscle glycogen: Comparison of iodine binding and enzyme digestion assays and application to meat samples. Meat Sci. 20:167-177.

Edwards, L. N., T. E. Engle, J. A. Correa, M. A. Paradis, T. Grandin, and D. B. Anderson. 2010a. The relationship between exsanguination blood lactate concentration and carcass quality in slaughter pigs. Meat Sci. 85:435-440.

Edwards, L. N., T. Grandin, T. E. Engle, S. P. Porter, M. J. Ritter, A. A. Sosnicki, and D. B. Anderson. 2010b. Use of exsanguination blood lactate to assess the quality of preslaughter pig handling. Meat Sci. 86:384-390.

Faucitano, L. 1998. Preslaughter stressors effects on pork: A review. J. Muscle Foods 9:293-303.

Foury, A., B. Lebret, P. Chevillon, A. Vautier, C. Terlouw, and P. Mormede. 2011. Alternative rearing systems in pigs: Consequences on stress indicators at slaughter and meat quality. Animal 5:1620-1625.

Hambrecht, E., J. J. Eissen, D. J. Newman, C. H. M. Smits, L. A. den Hartog, and M. W. A. Verstegen. 2005a. Negative effects of stress immediately before slaughter on pork quality are aggravated by suboptimal transport and lairage conditions. J. Anim. Sci. 83:440-448. 
Hambrecht, E., J. J. Eissen, D. J. Newman, C. H. M. Smits, M. W. A. Vertegen, and L. A. den Hartog. 2005b. Preslaughter handling effects on pork quality and glycolytic potential in two muscles differing in fiber type composition. J. Anim. Sci. 83: 900-907.

Hambrecht, E., J. J. Eissen, R. I. J. Nooijen, B. J. Ducro, C. M. H. Smits, L. A. den Hartog, and M. W. A. Verstegen. 2004. Preslaughter stress and muscle energy largely determine pork quality at two commercial processing plants. J. Anim. Sci. 82: 1401-1409.

Honikel, K. O. 1998. Reference methods for the assessment of physical characteristics of meat. Meat Sci. 49:447-457.

Joo, S. T., R. G. Kauffman, B. C. Kim, and G. B. Park. 1999. The relationship of sarcoplasmic and myofibrillar protein solubility to colour and water-holding capacity in porcine longissimus muscle. Meat Sci. 52:291-297.

Kauffman, R. G., G. Eikelenboom, P. G. van der Wal, G. Merkus, and M. Zaar. 1986. The use of filter paper to estimate drip loss of porcine musculature. Meat Sci. 18:191-200.

Kocwin-Podisiadla, M., E. Krzecio, and W. Przybylski. 2006. Pork quality and methods of its evaluation - A review. Pol. J. Food Nutr. Sci. 15/56:241-248.

Koknaroglu, H. and T. Akunal. 2013. Animal welfare: An animal science approach. Meat Sci. 95:821-827.

Lee, S. H., J. H. Choe, Y. M. Choi, K. C. Jung, M. S. Rhee, K. C. Hong, S. K. Lee, Y. C. Ryu, and B. C. Kim. 2012. The influence of pork quality traits and muscle fiber characteristics on the eating quality of pork from various breeds. Meat Sci. 90:284-291.

Mota-Rojas, D., M. Becerril-Herrera, P. Roldan-Santiago, M. Alonso-Spilsbury, S. Flores-Peinado, R. Ramirez-Necoechea, J. A. Ramirez-Telles, P. Mora-Medina, M. Perez, E. Molina, E. Soni, and M. E. Trujillo-Ortega. 2012. Effects of long distance transportation and $\mathrm{CO}_{2}$ stunning on critical blood values in pigs. Meat Sci. 90:893-898.
National Research Council. 1998. Nutrient Requirements of Swine, 10th ed. National Academy Press, Washington, DC, USA.

Ryu, Y. C., Y. M. Choi, and B. C. Kim. 2005. Variations in metabolite contents and protein denaturation of the longissimus dorsi muscle in various porcine quality classifications and metabolic rates. Meat Sci. 71:522-529.

Ryu, Y. C. and B. C. Kim. 2006. Comparison of histochemical characteristics in various pork groups categorized by postmortem metabolic rate and pork quality. J. Anim. Sci. 84: 894-901.

Scheffler, T. L. and D. E. Gerrard. 2007. Mechanisms controlling pork quality development: The biochemistry controlling postmortem energy metabolism. Meat Sci. 77:7-16.

Shaw, F. D. and R. K. Tume. 1992. The assessment of preslaughter and slaughter treatments of livestock by measurement of plasma constituents-A review of recent work. Meat Sci. 32:311-329.

Statistical Analysis System. 2009. SAS 9.2 SQL Procedure User's Guide. SAS Institute Inc., Cary, NC, USA.

van der Wal, P. G., B. Engel, and H. G. M. Reimert. 1999. The effect of stress, applied immediately before stunning, on pork quality. Meat Sci. 53:101-106.

Warner, R. D., P. L. Greenwood, D. W. Pethick, and D. M. Ferguson. 2010. Genetic and environmental effects on meat quality. Meat Sci. 86:171-183.

Warriss, P. D. 1990. The handling of cattle pre-slaughter and its effects on carcass and meat quality. Appl. Anim. Behav. Sci. 28:171-186.

Warriss, P. D. 2010. Meat Science-An Introductory Text, 2nd ed. CABI., Cambridge, UK.

Warriss, P. D., S. N. Brown, S. J. M. Adams, and I. K. Corlett. 1994. Relationships between subjective and objective assessments of stress at slaughter and meat quality in pigs. Meat Sci. 38:329-340. 